\title{
An Investigation of the Effect of Age, Severity of Hypertension and Duration of Hypertension for Erectile Dysfunction
}

\author{
Dr. Abdur Razzaque ${ }^{* 1}$, Dr. Farjana Parvin², Dr. S. M. Ruhul Amin³, Dr. Rashadul Kabir ${ }^{4}$, Dr. Md. Monowar Hossain ${ }^{5}$
}

\author{
${ }^{1}$ Assistant Professor, Department of Medicine, Shaheed Ziaur Rahman Medical College, Bogura, Bangladesh \\ ${ }^{2}$ Medical Officer, Upazilla Health Complex, Khetlal, Joypurhat, Bangladesh \\ ${ }^{3}$ Assistant Professor, Department of Medicine, Shaheed Ziaur Rahman Medical College, Bogura, Bangladesh \\ ${ }^{4}$ Assistant Professor, Department of Medicine, Shaheed Ziaur Rahman Medical College, Bogura, Bangladesh \\ ${ }^{5}$ Assistant Professor, Department of Medicine, Shaheed Ziaur Rahman Medical College, Bogura, Bangladesh
}

DOI: $10.36347 /$ sasjm.2021.v07i05.011

| Received: 28.03.2021 | Accepted: 06.05.2021 | Published: 30.05.2021

*Corresponding author: Dr. Abdur Razzaque

Abstract

Original Research Article

Introduction: Hypertension (HTN) is one of the most common diseases of the cardiovascular system. It is an increasingly important medical and public health problem. Hypertension is regarded as an indicator for erectile dysfunction. That is why problems with erectile function are an important concern in the treatment of hypertension. Objective: To investigate the frequency and severity of erectile dysfunction among hypertensive and normotensive married men attending a tertiary care hospital of Bangladesh. Material \& Methods: It was a cross sectional comparative study. The study was done at Shaheed Ziaur Rahman Medical College, Bogura, Bangladesh in the department of Medicine from July 2019 to January 2021. A total of 150 patients were selected as a study population. Purposive sampling was applied to collect the sample as per inclusion and exclusion criteria. The participants who were excluded from the study declined to give their consent, didn't complete the questionnaire and there was difficulties in fulfilling the inclusion and exclusion criteria. After collecting the data, it was checked and rechecked for omission, inconsistencies and improbabilities. Data analysis was performed by Statistical Package for Social Science (SPSS), version-22. Results: Analysis was done with the data of 150 cases. Out of the total 150 cases 75 were hypertensive and 75 were normotensive. The respondents were further sub grouped into an age matched manner. The predominant respondent age group was 40 to 49 years which included 42 in normotensive group and 42 in hypertensive group. The age range of the normotensive was 33-55 years in the study population and the mean age of them was $(42.65 \pm 5.53)$ years. On spot measurement of blood pressure 26 patients were found in an uncontrolled state of BP. Fifteen (15) subjects was in grade I and 11 subjects were in grade II. Among them 53.3\% of grade 1 had ED and $90.9 \%$ with grade II suffered from ED. None was found in the range of grade III or Isolated systolic hypertension. The result was significant $(\mathrm{p}=0.041)$. The longer duration of hypertension was significantly associated with ED ( $p$ value was $<0.001)$. The respondents who had hypertension and age $>50$ years were significant risk factors for ED group. Hypertension is 2.017 times more risk for ED to compare non-hypertensive respondents $(\mathrm{OR}=2.017$ with $95 \%$ CI 1.003-4.052) and age more than 50 years with hypertension 3.06 times more risk for ED to compare age less than 50 years $(\mathrm{OR}=3.063$ and $95 \% \mathrm{CI}=(1.421-6.604)$. Conclusion: Hypertensive patients present with erectile dysfunction more frequently than age matched normotensive individuals. As erectile dysfunction is a matter of embarrassment, doctors should be motivated to discuss such issue.

Keywords: Hypertension (HTN), Erectile Dysfunction(ED), Internal Medicine, Blood Pressure (BP).

Copyright $\odot 2021$ The Author(s): This is an open-access article distributed under the terms of the Creative Commons Attribution 4.0 International License (CC BY-NC 4.0) which permits unrestricted use, distribution, and reproduction in any medium for non-commercial use provided the original author and source are credited.

\section{INTRODUCTION}

Hypertension (HTN) is one of the most common diseases of the cardiovascular system. It is an increasingly important medical and public health problem. Doumas et al., [1] conducted a study upon 634 consecutive young and middle-aged men (31-65 years) who visited the outpatient clinic in the Department of Internal Medicine, University of Athens, Greece. From them, 358 patients had arterial hypertension and 276 were normotensive. International Index for Erectile Function questionnaire was used by them to evaluate erectile dysfunction. They found erectile dysfunction in $35.2 \%$ of patients with essential hypertension compared with $14.1 \%$ of normotensive subjects. About $26.4 \%$ of the adult population was affected by HTN in 2000. The number of adults with hypertension in 2025 is likely to 
rise by about $60 \%$ Kearney et al., [2]. In Bangladesh, around $20 \%$ of adult and $40-65 \%$ of elderly people suffer from HTN Islam and Majumder [3]. Hypertension is associated with stroke, coronary heart disease, congestive heart failure and renal failure Chobanian et al., [4]. It is a well-established indicator of erectile dysfunction (ED). About $30 \%$ to $50 \%$ of hypertensive men are affected by ED Nunes et al., [5]. Erectile dysfunction(ED) is almost twice common in hypertensive patients in comparison to normotensive Greek individuals Doumas et al., [6]. Sexuality is an important human need. It also determines individuals' subjective satisfaction and affects each person's perception and feelings. Male sexual function has three components: libido or sexual desire; erectile function or arousal; and orgasm or ejaculation. Erectile function is highly cherished by the majority of males, even at older ages. Erectile dysfunction (ED) is the regular inability to achieve and/or maintain an erection sufficient to permit satisfactory sexual intercourse National Institutes of Health [7]. It exerts a major burden on the quality of life of the patients and their sexual partners. Erectile dysfunction is a condition of increasing prevalence worldwide, which has been estimated to affect 150 million individuals and is supposed to impact up to $50 \%$ of men between the ages of 40-70 years Johannes et al., [8]. Diminished sexual function is a natural part of the aging process and the incidence of hypertension also increases with age Bacon et al., [9]. In about $40 \%$ of men over 50 years old, the primary reason of erectile dysfunction is related to atherosclerosis Kaiser et al., [10]. Diabetes mellitus, hypertension, heart disease, and poly pharmacy are more frequent in aged people and have been directly associated to erectile dysfunction. The Massachusetts Male Aging Study (MMAS) described the prevalence of moderate-to- severe erectile dysfunction between the ages of 40 and 70 years which is increased approximately 2 to 3-fold Feldman et al., [11]. Whenever patients on antihypertensive drugs experience sexual problems, they very often modify or even discontinue the treatment. But scientific data that links antihypertensive medication to erectile dysfunction in placebo-controlled trials is very limited Prisant et al., [12]. There are various proposed sexual dysfunction related side effects of various antihypertensive drugs. Adverse effects of thiazide and thiazide-like diuretics on male sexual function, including decreased libido, erectile dysfunction, and difficult ejaculation have been reported in several studies with an incidence that varies from 3\%-32\% Grimm et al., [13]. Impotence and decreased libido are the more frequent sexual side effects with spironolactone Bansal [14].

\section{OBJECTIVES}

\section{a) General objective:}

- To investigate the frequency and severity of erectile dysfunction among hypertensive and normotensive married men attending a tertiary care hospital of Bangladesh.

b) Specific Objectives:

- To find out the frequency of erectile dysfunction among hypertensive and normotensive married men attending in a tertiary care hospital of Bangladesh.

- To find out the severity of erectile dysfunction among hypertensive and normotensive married men attending in a tertiary care hospital of Bangladesh.

\section{METHODOLOGY AND MATERIALS}

It was a cross sectional comparative study.The study done at Shaheed Ziaur Rahman Medical College, Bogura, Bangladesh in the department of Medicine from July 2019 to January 2021.A total of 150 patients were selected as a study population. Purposive sampling was applied to collect the sample as per inclusion and exclusion criteria. It was a hospital-based study with age group of 20 to 59 years patients with HTN and age matched normotensive married men. It was based on randomly selected 125 normotensive and 120hypertensive married men who visited theoutpatient department of Internal medicine, Bangabandhu Sheikh Mujib Medical University, for any reason. Of the 125 normotensive and 120 hypertensive participants who were approached for the study $100(80 \%)$ normotensive participants and $105(87.5 \%)$ hypertensive participants gave their written consent to participate. they were included in the study. Later on, age matched control was done. The participants who were excluded from the study declined to give their consent, didn't complete the questionnaire and there was difficulties in fulfilling the inclusion and exclusion criteria. After collecting the data, it was checked and rechecked for omission, inconsistencies and improbabilities. Data analysis was performed by Statistical Package for Social Science (SPSS), version-22. The frequency and severity of erectile dysfunction and other categorical variables were reported as proportion with $95 \%$ confidence interval. The categorical data were compared by chisquare test followed by logistic regression analysis as a significant level of $0.05 \%$. Logistic regression analysis was employed to determine the factors related to erectile dysfunction.

\section{- Inclusion Criteria}

- Age of 20 years to 59 years

- Gender : male

- Married state and active sexual relationship with wife or wives for at least the past 6 months

- Known hypertensive for at least 6 months

- Agree to participate and sign the informed consent ( irrespective of medication and status)

- Capable to answer a self-applied questionnaire 


\section{- Exclusion Criteria}

- Known major medical illness (e.g. renal, hepatic or cardiovascular disease)

- Known prostate disease

- Bedbound patient due to any illness

- Any limitation that impairs patient's capability to understand the informed consent Patients taking antipsychotic or antidepressant medication

- A history of substance or drug abuse

\section{RESULTS}

Analysis was done with the data of 150 cases. Out of the total 150 cases 75 were hypertensive and 75 were normotensive. The respondents were further sub grouped into an age matched manner. Though selection criteria included 20 to 59 years of age group; none was found in the range of 20 to 29 years age. So, the study subjects were subdivided into 30-39 years, 40- 49 years and $50-59$ years. The predominant respondent age group was 40 to 49 years which included 42 in normotensive group and 42 in hypertensive group. The age range of the normotensive was 33-55 years in the study population and the mean age of them was $(42.65$ \pm 5.53 ) years. Analysis was done with the data of 150 cases. Out of the total 150 cases 75 were hypertensive and 75 were normotensive. The respondents were further sub grouped into an age matched manner. Though selection criteria included 20 to 59 years of age group; none was found in the range of 20 to 29 years age. So, the study subjects were subdivided into $30-39$ years, 40- 49 years and $50-59$ years. The predominant respondent age group was 40 to 49 years which included 42 in normotensive group and 42 in hypertensive group. The age range of the normotensive was 33-55 years in the study population and the mean age of them was $(42.65 \pm 5.53)$ years. On the other hand, the age range of the hypertensive was $30-59$ years. Mean age was $(44 \pm 7.4)$ years. The unpaired ttestshowed no significant difference between two mean age group. In both the hypertensive and normotensive study subjects, most of the respondents came from rural area which included $81.3 \%$ in normotensive population and $70 \%$ in hypertensive population. Few subjects $(8 \%)$ were illiterate in both normotensive and hypertensive group. Most of the participants $(32 \%)$ in normotensive group completed primary education and in the hypertensive group most $(28 \%)$ of the respondents were graduate. In respect of occupation it was found that large number of subjects was private service holder which included $57.3 \%$ and $49.3 \%$ in normotensive and hypertensive group respectively. Most of the participants were from lower socioeconomic background. They were $68 \%$ in normotensive group and $66.7 \%$ in hypertensive group. Regarding personal habits $41.3 \%$ among the normotensive and $38.7 \%$ among the hypertensive were indulging in smoking and tobacco leaf chewing. The difference between two groups was non-significant $(p=0.738)$. There was insignificant $(p=0.141)$ association of BMI with blood pressure in hypertensive and normotensive population (Table I). On spot measurement of blood pressure 26 patients were found in an uncontrolled state of BP. Fifteen (15) subjects was in grade I and 11 subjects were in grade II. Among them $53.3 \%$ of grade 1 had ED and $90.9 \%$ with grade II suffered from ED. None was found in the range of grade III or Isolated systolic hypertension. The result was significant ( $p=0.041$ ) (Table II). Patients with HTN were subdivided on the basis of their duration. The longer duration of hypertension was significantly associated with ED (p value was <0.001) (Table I I I ). The respondents who had hypertension and age $>50$ years were significant risk factors for ED group. Hypertension is 2.017 times more risk for $\mathrm{ED}$ to compare non-hypertensive respondents ( $\mathrm{OR}=2.017$ with $95 \%$ CI 1.003-4.052) and age more than 50 years with hypertension 3.06 times more risk for ED to compare age less than 50 years $(\mathrm{OR}=3.063$ and $95 \%$ $\mathrm{CI}=($ 1.421-6.604) (Table IV). IIEF-5 score are significantly moderately negative correlation with age and weak negative correlation with BMI (Table -V).

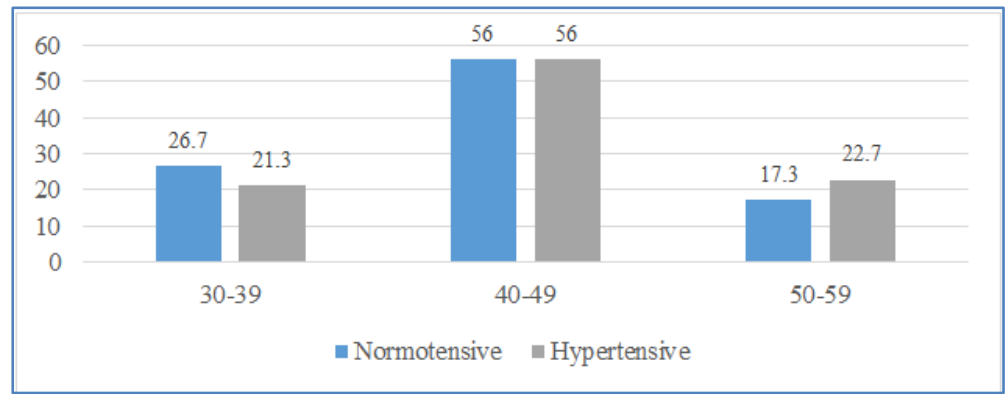

Fig-1: Bar diagram showing the age distribution of the study subjects. $(n=150)$

Table-1: Demographic characteristics of the study subjects $(n=150)$

\begin{tabular}{|l|l|l|l|}
\hline Demographic variables & Normotensive $(\mathbf{n = 7 5})$ No. $(\%)$ & Hypertensive $(\mathbf{n = 7 5})$ No. $(\%)$ & p value \\
\hline Age group (in years) & $20(26.7)$ & $16(21.3)$ & \\
\hline $\mathbf{3 0 - 3 9}$ & $42(56.0)$ & $42(56.0)$ & \multirow{2}{*}{0.376} \\
\hline $\mathbf{4 0 - 4 9}$ & $13(17.3)$ & $17(22.7)$ & $75(100.0)$ \\
\hline $\mathbf{5 0 - 5 9}$ & $75(100.0)$ & & \\
\hline Total &
\end{tabular}




\begin{tabular}{|c|c|c|c|}
\hline Demographic variables & Normotensive $(n=75)$ No. $(\%)$ & Hypertensive (n=75) No. (\%) & p value \\
\hline Mean \pm SD & $42.65 \pm 5.53$ & $44.0 \pm 7.4$ & \\
\hline Range & $(33-55)$ yrs. & (30-59) yrs. & \\
\hline \multicolumn{4}{|l|}{ Residence } \\
\hline Urban & $14(18.7)$ & $22(29.3)$ & \multirow[b]{2}{*}{0.126} \\
\hline Rural & $61(81.3)$ & $53(70.0)$ & \\
\hline \multicolumn{3}{|l|}{ Occupational status } & \\
\hline Unemployed/Dependent & $1(1.3 \%)$ & $1(1.3 \%)$ & \multirow{7}{*}{0.901} \\
\hline Farmer & $2(2.7 \%)$ & $4(5.3 \%)$ & \\
\hline Businessman & $17(22.7 \%)$ & $17(22.7 \%)$ & \\
\hline Government jobs & $3(4.0 \%)$ & $6(8.0 \%)$ & \\
\hline Private service & $43(57.3 \%)$ & $37(49.3 \%)$ & \\
\hline Workers & $6(8.0 \%)$ & $7(9.3 \%)$ & \\
\hline Other & $3(4.0 \%)$ & $4(5.0 \%)$ & \\
\hline \multicolumn{3}{|l|}{ Level of education } & \\
\hline Illiterate & $6(8.0 \%)$ & $6(8.0 \%)$ & \multirow{6}{*}{0.581} \\
\hline Primary & $24(32.0 \%)$ & $18(24.0 \%)$ & \\
\hline Secondary & $14(18.7 \%)$ & $11(14.7 \%)$ & \\
\hline Higher secondary & $11(14.7 \%)$ & $12(16.0 \%)$ & \\
\hline Graduate & $12(16.0 \%)$ & $21(28.0 \%)$ & \\
\hline Post Graduate & $8(10.7 \%)$ & $7(9.3 \%)$ & \\
\hline \multicolumn{4}{|l|}{ Socioeconomic status } \\
\hline $\begin{array}{l}\text { Lower income group } \\
(<5000 \mathrm{Tk} / \mathrm{month})\end{array}$ & $51(68.0 \%)$ & $50(66.7 \%)$ & \multirow{3}{*}{0.581} \\
\hline $\begin{array}{l}\text { Middle income group } \\
\text { (5000-50000 Tk/month) }\end{array}$ & $17(22.7)$ & $14(18.7 \%)$ & \\
\hline $\begin{array}{l}\text { Upper income group } \\
(>50000 \mathrm{Tk} / \mathrm{month})\end{array}$ & $7(9.3 \%)$ & $14(18.7 \%)$ & \\
\hline \multicolumn{3}{|c|}{ Smoking and tobacco leaf chewing } & \\
\hline Yes & $31(41.3 \%)$ & $29(38.7 \%)$ & \multirow[t]{2}{*}{0.738} \\
\hline No & $44(58.7 \%)$ & $46(61.3 \%)$ & \\
\hline \multicolumn{4}{|l|}{ BMI $\left(\mathrm{kg} / \mathrm{m}^{2}\right)$} \\
\hline Underweight $(<18.5)$ & $2(2.7 \%)$ & $1(1.3 \%)$ & \multirow[t]{4}{*}{0.141} \\
\hline $\begin{array}{l}\text { Normal weight (18.5- } \\
\text { 24.99) }\end{array}$ & $59(78.7 \%)$ & $48(64.0 \%)$ & \\
\hline Overweight (25-29.99) & $12(16.0 \%)$ & $24(32.0 \%)$ & \\
\hline Obese $(>30)$ & $2(2.7 \%)$ & $2(2.7 \%)$ & \\
\hline
\end{tabular}

Data were expressed as frequency and percentage. Chi-square test was done to see the association of personal habits between groups

Table-2: Association of grading of hypertension (HTN) and presence of erectile dysfunction (ED) (n=26)

\begin{tabular}{|l|l|l|l|l|}
\hline Grade of Hypertension & \multirow{2}{*}{ N } & \multicolumn{2}{|l|}{ Severity of ED (range of IIEF 5score) } & \multirow{2}{*}{ P value } \\
\cline { 3 - 4 } & & Present $(\mathbf{n}=\mathbf{1 8})$ & Absent (n=8) & \\
\hline Grade I & 15 & $8(53.3 \%)$ & $7(87.5 \%)$ & \multirow{2}{*}{0.041} \\
\hline Grade II & 11 & $10(90.0 \%)$ & $1(12.5 \%)$ & \\
\hline Total & 26 & $18(100 \%)$ & $8(100 \%)$ & \\
\hline
\end{tabular}

Data were expressed as frequency and percentage. Fisher exact test was done to see the association of severity of erectile dysfunction with grading of HTN 


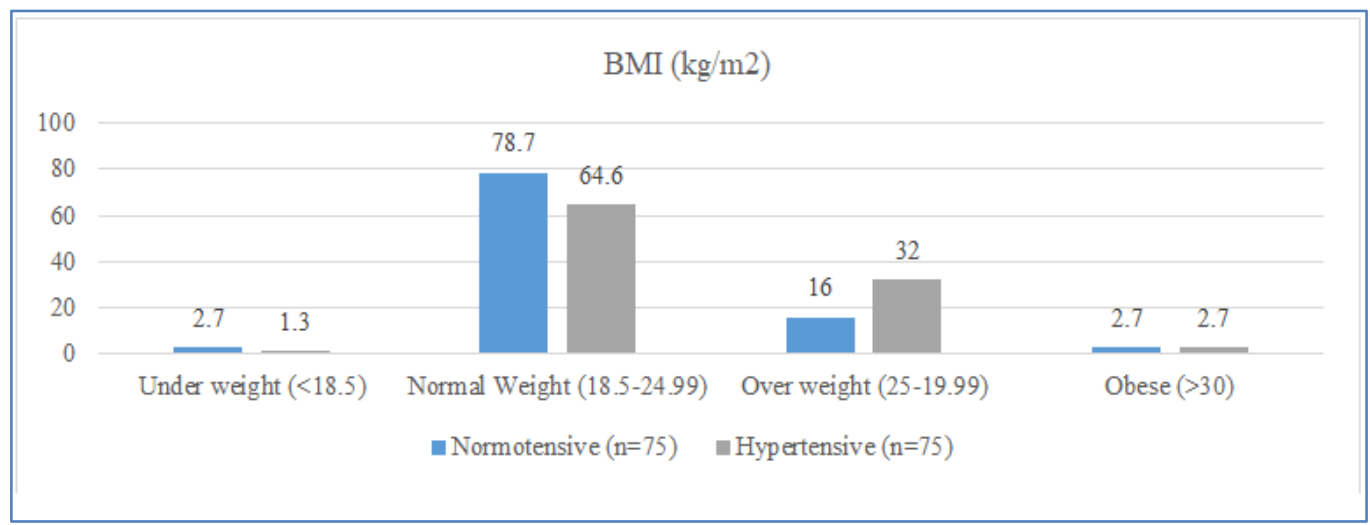

Fig-2: Pearson Correlation test was done for age and Body Mass Index (BMI) to see their correlation with erectile dysfunction. $(n=150)$

Table-3: Association of duration of hypertension (HTN) with erectile dysfunction (ED) (n=75)

\begin{tabular}{|l|l|l|l|l|}
\hline \multirow{2}{*}{ Duration of HTN (Years) } & \multirow{2}{*}{ No of patients } & \multicolumn{2}{|l|}{ Severity of ED (range of IIEF 5score) } & \multirow{2}{*}{ P value } \\
\cline { 3 - 4 } & & Present (n=18) & Absent (n=8) & \\
\hline $\mathbf{5}$ & $25(33.3 \%)$ & $4(16.0 \%)$ & $21(84.0 \%)$ & \multirow{3}{*}{0.001} \\
\hline $\mathbf{5 - 9}$ & $22(29.3 \%)$ & $16(72.7)$ & $6(27.3 \%)$ & \\
\hline $\mathbf{1 0 - 1 4}$ & $19(25.3 \%)$ & $18(94.7 \%)$ & $1(5.3 \%)$ & \\
\hline$>\mathbf{1 4}$ & $9(12.0 \%)$ & $8(88.9 \%)$ & $1(11.1 \%)$ & \\
\hline Total & $75(100 \%)$ & $46(61.1 \%)$ & $29(42.7 \%)$ & \\
\hline
\end{tabular}

Data were expressed as frequency and percentage, Chi-square test done to see the association of erectile dysfunction with duration of hypertension

Table-4: Prediction of erectile dysfunction (ED) from hypertension (HTN) and age.

\begin{tabular}{|l|l|l|l|l|l|l|l|}
\hline Variable & Parameter estimates & S.E. & Df & P value & OR & \multicolumn{2}{|l|}{ 95\% CI } \\
\cline { 5 - 8 } & & & & & & Lower & Upper \\
\hline Hypertension (Yes) & 0.701 & .356 & 1 & .049 & 2.017 & 1.003 & 4.052 \\
\hline Age (>50 yrs.) & 1.119 & .392 & 1 & .004 & 3.063 & 1.421 & 6.604 \\
\hline
\end{tabular}

Multivariate logistic regression analysis was done

Table -5: Correlation of IIEF-5 score with age and Body Mass Index (BMI). (n=150)

\begin{tabular}{|c|c|c|}
\hline \multicolumn{3}{|l|}{ IIEF-5 score } \\
\hline IIEF-5 score & Pearson Correlation Sig. (2-tailed) N & $\begin{array}{l}1 \\
150\end{array}$ \\
\hline Age (in Years) & Pearson Correlation Sig. (2-tailed) N & $\begin{array}{l}-3.359 * * \\
.000 \\
150\end{array}$ \\
\hline BMI & Pearson Correlation Sig. (2-tailed) N & $\begin{array}{l}-.151 \\
.065 \\
150\end{array}$ \\
\hline
\end{tabular}

Pearson Correlation test was done for age and Body Mass Index (BMI) to see their correlation with erectile dysfunction.

\section{DISCUSSION}

Hypertension is regarded as an indicator for erectile dysfunction. That is why problems with erectile function are an important concern in the treatment of hypertension. It often influences the choice of commencement or decision of discontinuation of antihypertensive medication. The results of this study supported the results of other study conducted by Giuliano et al., [15] in France, which found the overall prevalence of $61 \%$ ED among the 3906 patients with hypertension alone. A study conducted by Abdulbari et al.,[16] in Qatar showed that out of 296 hypertensive patients, 196(66.2\%) participants reported erectile dysfunction while among the 298 no hypertensive participants, only $71(23.8 \%)$ had erectile dysfunction. Of the hypertensive participants studied, $25 \%$ had severe, $29.1 \%$ had moderate, and $12.1 \%$ had mild erectile dysfunction. The percentages of different sexual activity domains were exceedingly notable and at higher risk among hypertensive patients than normotensive men $(\mathrm{p}<0.001)$. Nobody was found in the range of severe ED (IIEF-5 score 0-6) both in hypertensive and normotensive group in this study. In the moderate to severe range (IIEF-5 score 7-12) 
hypertensive is $5(6.7 \%)$ and the normotensive is $0(0 \%)$ out of 75 in each group ( $\mathrm{p}=0.022)$ which is significant and in the mild to moderatecategories(IIEF-5 score 1318 ) the hypertensive study subjects have more ED ( $\mathrm{p}=$ 0.045) .The mild group (IIEF -5 score 19-24) had a nonsignificant $(\mathrm{p}=1.00)$ difference in between the normotensive and hypertensive groups [13(17.3\%) in normotensive population and $14(18.7 \%)$ in hypertensive population] probably due to small sized sample. The normotensives had significantly much more percentage with no ED in comparison to hypertensives [ $62.7 \%$ vs $38.7 \%$ ] and the $\mathrm{p}$ is significant (0.005). A multicenter Spanish study reported a prevalence of ED is $45.8 \%$ in 2130 patients with hypertension Aranda et al.,[17].But Newman and Marus reported similar prevalence of ED in hypertensive and normotensive men Newman and Marus [18]. These controversies might be due to the nature of population examined, the sample size, and the type of tool used to evaluate erectile function. Although differences in prevalence rates of ED in case of hypertension exist, most of the studies showed a higher prevalence of ED in hypertensive than normotensive men. HTN increases the incidence of $\mathrm{ED}$, in an age-adjusted analysis Düsing, [19]. It is also prevalent in this study (OR 2.017; $95 \%$ CI 1.003 to 4.052 ). Several studies in different countries with various cultural backgrounds have confirmed that hypertension is one important disease of increased risk for ED. Akkus et al., [20-22]. It is important to note that: hypertensives have more erectile dysfunction than normotensives, most people who commence therapy for hypertension are generally older than 50 years, a time when sexual function is beginning to go downhill; and decreasing blood pressure by any means may affect penile blood flow, especially in people older than 60 years. Severity of HTN also influences the ED in severe form. Patients who suffer from grade II HTN have more severe ED than grade I HTN. On the other hand, patients who had a good control of BP had low ED than those who had uncontrolled HTN. Healthy older people also suffer from ED. Penile hemodynamic changes occurring in aging might account for erectile dysfunction because cavernous arterial flow is decreased, the response time of the cavernous artery is increased, and peak systolic velocity occurs much later in subjects after the fifth decade of life Chung et al., [23]. Frequency and severity of erectile dysfunction was increased with advancing age in a study conducted by Abdulbari et al., [16] the results of which were similar to the study on ED reported in Spain Martin-Morales et al ., [24]. In this study, increased age was found to correlate with erectile dysfunction in both hypertensive and normotensive individuals. IIEF-5 score had a significant negative correlation with age. Increased age was associated with decrease IIEF-5 score after paying attention to both the hypertensive and normotensive individuals. But the hypertensives showed a significant decrease in IIEF-5 score especially after the age of 50 years. The findings of this study showed the relation between the increasing age and increasing frequency of ED in hypertensive men. The mean IIEF-5 score decreased with the increased duration of hypertension among the evaluated hypertensive individuals in our study. It supports the observation done by Abdulbari et al., [16] in Qatar where it was found that the mean IIEF-5 score was decreased with the increased duration of hypertension. In another study it was also demonstrated that the patients who had a diagnosis of hypertension for less than 5 years had moderate ED (IIEF-5 score= $15.3 \pm 5.8)$, and patients who had hypertension for more than 10 years had severe ED (IIEF-5 score $=12.2 \pm 6.1$ ) Kushiro et al., [25]. It is confirmed that ED is highly correlated with vascular disease. Hypertension, dyslipidemia, diabetes, and smoking predict the risk of developing vascular disease and erectile dysfunction Kushiro et al., [25]. The studied hypertensive participants with smoking and tobacco leaf chewing habits had no significant association. Smoking and/or tobacco leaf chewing was explored among the study subjects who didn't have significant variation between the normotensive and hypertensive group. There are many recent observational studies on smoking and risk of erectile dysfunction (ED). The evidence available on the association between smoking and ED is inconclusive $\mathrm{Cao}$ et al., [26]. A literature review concluded that smokers are 1.5 times more likely to suffer from erectile dysfunction than non-smokers Dorey [27].In the baseline sample of the MMAS, smoking was not independently associated with erectile dysfunction, but it exacerbated the effects of heart disease, high blood pressure and antihypertensive medication Feldman et al., [28]. Smoking was not associated with ED in the whole follow-up sample Johannes et al., [8]. The association between smoking and / or tobacco leaf chewing with ED was not analyzed in this study. Obesity has been shown to increase the prevalence of ED in some studies Moreira et al.,Bacon et al.,Vallancien et al., [29,9,30]. Obese patients also have an increased prevalence of vascular risk factors Chung et al., [23]. In the MMAS, obesity was an independent predictor of ED Derby et al., [31]. Multiple cross-sectional studies have shown that over-weight (body mass index [BMI] 25 to $30 \mathrm{~kg} / \mathrm{m}^{2}$ ) and obese $\left(\right.$ BMI $\left.>30 \mathrm{~kg} / \mathrm{m}^{2}\right)$ men have an incremental increase in the risk of ED with the relative risk ranging from 1.5 to 3.0-fold Chitaley et al., [32]. A randomization was done in a prospective study by Esposito et al., [33] upon 55 men with ED to healthy behaviors (caloric reduction and consistent exercise) vs. control. After a follow- up of two years, the treatment arm averaged $15 \mathrm{~kg}$ of weight loss with $31 \%$ regaining normal erectile function compared to $2 \%$ in the control arm. Obesity in itself may not be a direct risk factor, but can induce vasculogenic impotence through increasing risk of chronic diseases including diabetes, hypertension, heart disease and hyperlipidemia. A weak negative correlation of increased BMI with decreased erectile functionality was found in both Hypertensive and normotensive study subjects. 


\section{Limitations of the Study:}

Being a hospital-based study, finding of this study are not generalized. It didn't include all the targeted population. Hypertension is recognized on the basis of self-reporting with minimum attempts to validate response with medical records or physicians' reports. Surely, it cannot reflect the actual scenario of the whole country.

\section{CONCLUSION AND RECOMMENDATIONS}

Hypertensive patients present with erectile dysfunction more frequently than age matched normotensive individuals. As erectile dysfunction is a matter of embarrassment, doctors should be motivated to discuss such issue. Control of blood pressure seems to confer good influence upon the prevalence of erectile dysfunction. This study doesn't reflect the actual scenario regarding the frequency and severity of ED among hypertensive and normotensive married men of Bangladesh. We need further studies to authenticate such observation and to unveil other risk factors of ED in our country and to go for appropriate management. Large epidemiological studies can be carried out to disclose the facts related to ED.Doctors should routinely inquire about ED, and can use the IIEF-5 to diagnose it, since it is important forerunner of cardiac disease as other cardiac risk factors.

Funding: No funding sources

Conflict of interest: None declared

Ethical approval: The study was approved by the Institutional Ethics Committee

\section{REFERENCES}

1. Doumas, M., \& Douma, S. (2006). The effect of antihypertensive drugs on erectile function: a proposed management algorithm. The journal of clinical hypertension, 8(5), 359-363.

2. Kearney, P. M., Whelton, M., Reynolds, K., Muntner, P., Whelton, P. K., \& He, J. (2005). Global burden of hypertension: analysis of worldwide data. The lancet, 365(9455), 217-223.

3. Islam, A. M., \& Majumder, A. A. (2012). Hypertension in Bangladesh: a review. Indian heart journal, 64(3), 319-323.

4. Chobanian, A. V., Bakris, G. L., Black, H. R., Cushman, W. C., Green, L. A., Izzo Jr, J. L., ... \& National High Blood Pressure Education Program Coordinating Committee. (2003). Seventh report of the joint national committee on prevention, detection, evaluation, and treatment of high blood pressure. hypertension, 42(6), 1206-1252.

5. Nunes, K. P., Labazi, H., \& Webb, R. C. (2012). New insights into hypertension-associated erectile dysfunction. Current opinion in nephrology and hypertension, 21(2), 163.

6. Doumas, M., Tsakiris, A., Douma, S., Grigorakis, A., Papadopoulos, A., Hounta, A., ... \& Giamarellou, H. (2006). Factors affecting the increased prevalence of erectile dysfunction in
Greek hypertensive compared with normotensive subjects. Journal of Andrology, 27(3), 469-477.

7. National Institutes of Health. (1993). NIH consensus conference on impotence. Journal of American Medical Association, 270, 83-90.

8. Johannes, C. B., Araujo, A. B., Feldman, H. A., Derby, C. A., Kleinman, K. P., \& McKINLAY, J. B. (2000). Incidence of erectile dysfunction in men 40 to 69 years old: longitudinal results from the Massachusetts male aging study. The Journal of urology, 163(2), 460-463.

9. Bacon, C. G., Mittleman, M. A., Kawachi, I., Giovannucci, E., Glasser, D. B., \& Rimm, E. B. (2003). Sexual function in men older than 50 years of age: results from the health professional followup study. Annals of internal medicine, 139(3), 161168.

10. Kaiser, F. E., Viosca, S. P., Morley, J. E., Mooradian, A. D., Davis, S. S., \& Korenman, S. G. (1988). Impotence and aging: clinical and hormonal factors. Journal of the American Geriatrics Society, 36(6), 511-519.

11. Feldman, H. A., Goldstein, I., Hatzichristou, D. G., Krane, R. J., \& McKinlay, J. B. (1994). Impotence and its medical and psychosocial correlates: results of the Massachusetts Male Aging Study. The Journal of urology, 151(1), 54-61.

12. Prisant, L. M., Carr, A. A., Bottini, P. B., Solursh, D. S., \& Solursh, L. P. (1994). Sexual dysfunction with antihypertensive drugs. Archives of internal medicine, 154(7), 730-736.

13. Grimm Jr, R. H., Grandits, G. A., Prineas, R. J., McDonald, R. H., Lewis, C. E., Flack, J. M., ... \& Stamler, J. (1997). Long-term effects on sexual function of five antihypertensive drugs and nutritional hygienic treatment in hypertensive men and women: Treatment of Mild Hypertension Study (TOMHS). Hypertension, 29(1), 8-14.

14. Bansal, S. U. D. H. I. R. (1988). Sexual dysfunction in hypertensive men. A critical review of the literature. Hypertension, 12(1), 1-10.

15. Giuliano, F. A., Leriche, A., Jaudinot, E. O., \& de Gendre, A. S. (2004). Prevalence of erectile dysfunction among 7689 patients with diabetes or hypertension, or both. Urology, 64(6), 1196-1201.

16. Bener, A., Al-Ansari, A., Al-Hamaq, A. O., Elbagi, I. E. A., \& Afifi, M. (2007). Prevalence of erectile dysfunction among hypertensive and nonhypertensive Qatari men. Medicina, 43(11), 870.

17. Aranda, P., Ruilope, L. M., Calvo, C., Luque, M., Coca, A., \& Gil De Miguel, Á. (2004). Erectile dysfunction in essential arterial hypertension and effects of sildenafil: results of a Spanish national study. American journal of hypertension, 17(2), 139-145.

18. Newman, H. F., \& Marcus, H. (1985). Erectile dysfunction in diabetes and hypertension. Urology, 26(2), 135-137. 
19. Düsing, R. (2005). Sexual dysfunction in male patients with hypertension. Drugs, 65(6), 773-786.

20. Akkus, E., Kadioglu, A., Esen, A., Doran, S., Ergen, A., Anafarta, K., \& Turkish Erectile Dysfunction Prevalence Study Group. (2002). Prevalence and correlates of erectile dysfunction in Turkey: a population-based study. European urology, 41(3), 298-304.

21. Seyam, R. M., Albakry, A., Ghobish, A., Arif, H., Dandash, K., \& Rashwan, H. (2003). Prevalence of erectile dysfunction and its correlates in Egypt: a community-based study. International journal of impotence research, 15(4), 237-245.

22. Berrada, S., Kadri, N., Mechakra-Tahiri, S., \& Nejjari, C. (2003). Prevalence of erectile dysfunction and its correlates: a population-based study in Morocco. International journal of impotence research, 15(1), S3-S7.

23. Chung, W. S., Park, Y. Y., \& Kwon, S. W. (1997). The impact of aging on penile hemodynamics in normal responders to pharmacological injection: a Doppler sonographic study. The Journal of urology, 157(6), 2129-2131.

24. Martin-Morales, A., Sanchez-Cruz, J. J., Saenz de Tejada, I., Rodriguez-Vela, L., Fernando JimenezCruz, J., \& Burgos-Rodriguez, R. (2001). Prevalence and independent risk factors for erectile dysfunction in Spain: results of the Epidemiologia de la Disfuncion Erectil Masculina Study. The Journal of urology, 166(2), 569-575.

25. Kushiro, T., Takahashi, A., Saito, F., Otsuka, Y., Soma, M., Kurihara, T., \& Kanmatsuse, K. (2005). Erectile dysfunction and its influence on quality of life in patients with essential hypertension. American journal of hypertension, 18(3), 427-430.
26. Cao, S., Yin, X., Wang, Y., Zhou, H., Song, F., \& Lu, Z. (2013). Smoking and risk of erectile dysfunction: systematic review of observational studies with meta-analysis. PloS one, 8(4), e60443.

27. Dorey, G. (2001). Is smoking a cause of erectile dysfunction? A literature review. British Journal of Nursing, 10(7), 455-465.

28. Feldman, H. A., Johannes, C. B., Derby, C. A., Kleinman, K. P., Mohr, B. A., Araujo, A. B., \& McKinlay, J. B. (2000). Erectile dysfunction and coronary risk factors: prospective results from the Massachusetts male aging study. Preventive medicine, 30(4), 328-338.

29. Moreira Júnior, E. D., Bestane, W. J., Bartolo, E. B., \& Fittipaldi, J. A. S. (2002). Prevalence and determinants of erectile dysfunction in Santos, southeastern Brazil. Sao Paulo Medical Journal, 120(2), 49-54.

30. Vallancien, G., Emberton, M., Harving, N., van MOORSELAAR, R. J. A., \& Alf-One Study Group. (2003). Sexual dysfunction in 1,274 European men suffering from lower urinary tract symptoms. The Journal of urology, 169(6), $2257-$ 2261.

31. Derby, C. A., Mohr, B. A., Goldstein, I., Feldman, H. A., Johannes, C. B., \& McKinlay, J. B. (2000). Modifiable risk factors and erectile dysfunction: can lifestyle changes modify risk? Urology, 56(2), 302-306.

32. Chitaley, K., Kupelian, V., Subak, L., \& Wessells, H. (2009). Diabetes, obesity and erectile dysfunction: field overview and research priorities. The Journal of urology, 182(6S), S45S50. 